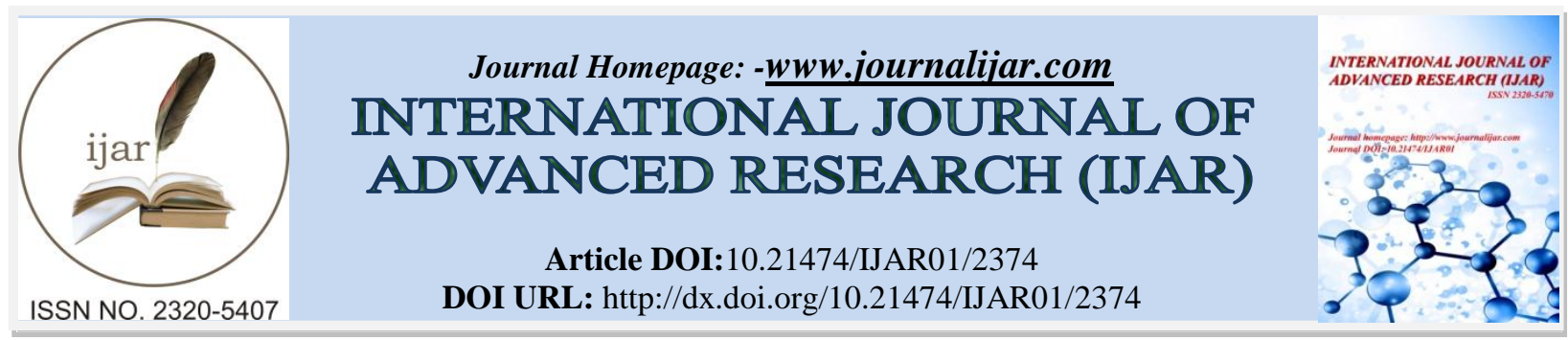

RESEARCH ARTICLE

\title{
PSYCHOSOCIAL DETERMINANTS TO GLYCEMIC CONTROL AMONG DIABETIC ADULTS ATTENDING ARMED FORCES HOSPITAL SOUTHERN REGION.
}

\author{
Ali A. Alshahrani, ${ }^{1}$ Ibrahim Arfaj, ${ }^{1}$ Ahmed Abu-Alyazeed, ${ }^{1}$ Saeed Hanbali,1 Faisal Bana, ${ }^{2}$ Nidal Muheisen, \\ Mohammed Ramahi. ${ }^{1}$ \\ Family Medicine Department, ${ }^{2}$ Internal Medicine Department, Forces Hospital, Southern Region, Saudi Arabia.
}

\section{Manuscript Info}

Manuscript History

Received: 18 October 2016

Final Accepted: 20 November 2016

Published: December 2016

Key words:-

HBA1c, depression, anxiety, stress, DASS-21.

\section{Abstract}

Background: Although there are some international and regional prevalence studies on psychological issues in diabetic patients, there is a paucity of epidemiological estimates on the prevalence, characterization and risk factors of depression, anxiety and stress among diabetics in Saudi Arabia.

Objectives: To find out the magnitude of depression, anxiety, stress symptoms and some social factors among diabetic patients with their predictions and association to glycemic control.

Subjects and methods A case-control study was implemented at AhadRufaidah, Southern Region, Saudi Arabia where the glycemic uncontrolled patients (cases) were compared to those who were controlled (controls) regarding the prevalence of psychological symptoms and other related social and demographic factors.A consecutive sample of adult diabetic patients registered at the diabetic centers in armed forces hospital was chosen. Participants were classified into two groups, i.e., glycemic uncontrolled patients group and controlled glycemic group.A self-administered questionnaire was developed and used for collection of data. It includes personal characteristics diabetes-related variables and the Arabic version of the Depression, Anxiety, and Stress Scale (DASS-21).

Results: The study included 395 patients. Their age ranged between 18 and 90 years with a mean \pm SD of $53.9 \pm 13.1$ years Most of them were males $(70.1 \%)$. Depression was reported among more than half of the participants $(51.9 \%)$ whereas anxiety and depression were reported among $70.1 \%$ and $37.7 \%$ of them, respectively. Glycated hemoglobin level was not significantly associated with depression, anxiety or stress. Among studied demographic and social factors, only marital status and smoking history were significantly associated with glycemic control. Single patients were more likely to have uncontrolled diabetes compared to married patients $(95.2 \%$ versus $65.3 \%$ ), $\mathrm{p}=0.025$. Smokers were more likely to have uncontrolled diabetes compared to non-smokers $(87.5 \%$ versus $65.6 \%), \mathrm{p}=0.007$.

Conclusion: There is evidence of high co-morbidity of diabetes and depression, anxiety and stress symptoms in Saudi Arabia. However, glycemic control according to HBA1c level was not associated with psychological issues in diabetic patients. 


\section{Introduction:-}

Diabetes mellitus is a chronic disease that requires long-term medical attention to limit the development of its complications, and to manage them when they occur. ${ }^{1}$ It affects more than 220 million patients worldwide, with approximately $90 \%$ having type 2 diabetes (DM2). ${ }^{2}$

The world is witnessing a growing pandemic of diabetes mellitus. Its rapid rise in incidence is of alarming concern to health care professionals. The main burden of this pandemic will fall primarily on developing countries. ${ }^{3}$ The estimated number of diabetic patients will reach 300 million by $2025,{ }^{4}$ which will have a significant impact on the limited health resources of the developing countries, as diabetes is a chronic disease with devastating complications. ${ }^{5}$

The Kingdom of Saudi Arabia has a relatively young population whose lifestyle has witnessed major changes in the last few decades. A significant rise in the incidence of diabetes has accompanied these lifestyle changes. In the late 1970s and early 1980s, diabetes was not considered a commonly encountered medical diagnosis in Saudi Arabia even in high-risk groups, and among the male Saudi population the prevalence of diabetes was not different from other parts of the world. ${ }^{5}$ This seems to have changed dramatically, as the prevalence of diabetes in Saudi Arabia has become one of the highest in the world. ${ }^{6}$

Many adults with diabetes consider stress to be a powerful determinant of their ability to maintain good metabolic control. $^{7}$ Higher levels of stress are associated with poorer glycemic control in adolescents ${ }^{8}$ and adults ${ }^{9}$ although there are very high levels of inter-individual variability.

Like depression and other negative mood states, ${ }^{10}$ stress may affect metabolic control indirectly by disrupting the individual's ability to manage diabetes effectively. ${ }^{11}$ Furthermore, elevated stress levels may affect metabolic control more directly by stimulating the autonomic nervous system to initiate a series of neuro-endocrine responses that raise circulating blood glucose and catecholamine levels 12and alter the activity of the hypothalamic-pituitary-axis, which may, in turn, further disrupt metabolic regulation and brain function. ${ }^{13}$

Bogner et al. ${ }^{14}$ has shown that the all cause mortality risk decreased when treating depression in primary care patients with diabetes mellitus. Given the high prevalence of depression in patients with DM2, and the fact that these emotional problems are often overlooked and undertreated, while effective treatments are available, current guidelines recommend screening for depression. ${ }^{15}$

Cross-sectional studies of adults with either T1DM or T2DM have demonstrated repeatedly that rates of psychological distress, particularly depression and anxiety, tend to be higher than the general population, but are usually comparable to those reported in individuals with other chronic diseases. ${ }^{16}$

Although there are some international and regional prevalence studies on psychological issues in diabetic patients, there is a paucity of epidemiological estimates on the prevalence, characterization and risk factors of depression, anxiety and stress among diabetics in Saudi Arabia. An estimate of the prevalence of these conditions is the first step towards priority setting and the planning, implementation and evaluation of psychological management intervention Program in diabetes care in the primary care setting.

The present study aims to find out the magnitude of depression, anxiety, stress symptoms and some social factors among diabetic patients with their predictions and association to glycemic control.

\section{Patients and methods:-}

A case-control study design was implemented where the glycemic uncontrolled patients (cases) were compared to those who were controlled (controls) regarding the prevalence of psychological symptoms and other related social and demographic factors.

This study was conducted at AhadRufaidah City, which is one of the main Aseer Region cities, Southern Saudi Arabia. 
Patients eligible for treatment at armed forces hospital are those who belong to ministry of defense as employee (military, civil) including non Saudi employees as well as their $1^{\text {st }}$ degree relatives excluding their brothers and sisters. They come from different places of southern region Saudi Arabia.

All diabetic patients registered at the above-mentioned diabetic centers and fulfilling the inclusion criteria constitute the study population. A simple random sample was followed to choose the clinics for data collection atAhadRufaidah and Diabetes center.

The minimum sample size for this study has been decided according to Swinscow and Cohen (2003) ${ }^{17}$ as follows:

$$
\mathrm{n}=\frac{\mathrm{Z}^{2} \times \mathrm{PXQ}}{\mathrm{D}^{2}}
$$

Where:n: Calculated sample size, Z: The z-value for the selected level of confidence $=1.96$, P: Estimated prevalence in the population $=34 \%$, i.e., 0.34 .

Q: $(1-\mathrm{P})=66 \%$, i.e., 0.66 and D: The maximum acceptable error [precision level] $=0.05$.

$$
\mathrm{n}=\frac{1.96^{2} \times 0.34 \times 0.66}{0.05^{2}}=\frac{3.8416 \times 0.25}{0.0025}=344
$$

A consecutive sample was followed at all diabetic clinics to include a total of 344 diabetic adult attendants at Armed Forces Hospital chosen diabetic clinics. Participants were classified into two groups, i.e., glycemic uncontrolled patients group and controlled glycemic group.

Inclusion criteria were diabetic patients aged above 18 years, registered at anyone of the abovementioned two diabetic polyclinic centers at armed forces hospital southern region and hbAlc test was done in the last 3 months at the time of questionnaire collection. Patients using antipsychotic and/or mood disorders medications, those having neurological diseases like dementia or Alzheimer's disease and those with hbA1c done more than 3 months at the time of questionnaire collection were excluded from the study.

A self-administered questionnaire was developed and used for collection of data. It includes personal characteristics (Age, sex, education, employment, marital status, presence of co morbidity), diabetes-related variables (duration of disease, treatment modality "insulin or oral hypoglycemic, number of daily injections", compliance to medication and lifestyle modification like exercise), social support related variable (when to rely on at the time of social and/or environmental stress conditions) and the Arabic versionoftheDASS-21(Depression, Anxiety, and Stress Scale). ${ }^{18,} 19$ The purpose of the questions is to assess the severity of the core symptoms of depression, anxiety, and stress. Each question measured the prevalence of symptoms of depression, anxiety or stress over the prior week .Answers were reported on a four Likert score (0-3). A score of 0 indicated that the item "did not apply to them," and a score of 3 mean that the participant considered the question to apply "very much, or most of the time". ${ }^{18}$

The scale to which each item belongs is indicated by the letters D (Depression), A (Anxiety) and S (Stress). For each scale (D, A \& S) sum the scores for identified items. Because the DASS 21 is a short form version of the DASS (the Long Form has 42 items), the final score of each item groups (Depression, Anxiety and Stress) was multiplied by two. Once multiplied by 2 , each score was transferred to the DASS profile sheet, enabling comparisons to be made between the three scales and also giving percentile rankings and severity labels.

Table 1:-DASS Severity Ratings.

\begin{tabular}{|c|c|c|c|}
\hline Severity & Depression & Anxiety & Stress \\
\hline Normal & $0-9$ & $0-7$ & $0-14$ \\
\hline Mild & $10-13$ & $8-9$ & $15-18$ \\
\hline Moderate & $14-20$ & $10-14$ & $19-25$ \\
\hline Severe & $21-27$ & $15-19$ & $26-33$ \\
\hline Extremely Severe & $28+$ & $20+$ & $34+$ \\
\hline
\end{tabular}

Last Hemoglobin A1c level in the past 3 months of the patient visit was assessed for the patient glycemic control. The level of control of diabetes as indicated by Hemoglobin A1c level was determined according to American Diabetes Association guideline for glycemic control in diabetic patients as follows: Controlled $\leq 7$ and uncontrolled $>7 .^{20}$ 
All the necessary official permissions were obtained before data collection. prior to data collection, all potential participants were briefed by the interviewer regarding the objectives of this study. They were assured that no harm was ever expected to occur if they decide to participate in this study. They were also be assured about the anonymity and full confidentiality of their responses. Their verbal consents to participate were then being requested. All diabetic subjects who obtain higher scores were screened by diagnostic tool like DSM V and were referral to a psychiatrist to establish the final diagnosis and to start management accordingly.

The Statistical Package for Social Sciences (SPSS version22.0) was used for computerized data entry and analysis. Descriptive statistics were computed and appropriate tests of significance were applied accordingly $\left(\chi^{2}\right.$-test and crude odds ratios). Differences were considered as statistically significant when the p-value is less than 0.05 .

\section{Results:-}

The study included 395 patients. Their age ranged between 18 and 90 years with a mean \pm SD of $53.9 \pm 13$.1years with more than half of them (52.4\%) aged between 41 and 60 years. Most of them were males (70.1\%). More than onequarter of them (28.3\%) were illiterate. Almost half of them (47.3\%) were not working whereas $16.5 \%$ were military persons. Majorities were married (86.8\%). Family size exceeded 10 persons among $22.8 \%$ of them. Almost twothirds of them $(62.3 \%)$ described their financial status as good. Prevalence of smoking was $8.1 \%$. Table 1

Table 2 summarized the medical and social characteristics of the diabetic patients. The duration of the disease ranged between one and five years among almost one-third of them (33.7\%) whereas it exceeded 15 years among $14.7 \%$ of them. Co-morbid diseases were reported among $45.6 \%$ of them, mainly hypertension (42.3\%). Majority of them $(87.6 \%)$ claimed that they are compliant with diabetic therapy. More than half of them reported practicing irregular physical activity $(56.7 \%)$ whereas $24.8 \%$ of then never practiced any physical activity. Insulin therapy was reported among $29.6 \%$ of the participants. Two doses of insulin per day were reported among $59.9 \%$ of them. Social support was reported among majority of them (78.2\%). Glycatedhaemoglobin was $\geq 7 \%$ among almost two-thirds of the participants $(67.3 \%)$.

As displayed in figure 1, depression was reported among more than half of the participants (51.9\%) whereas anxiety and stress were reported among $70.1 \%$ and $37.7 \%$ of them, respectively.

Among studies factors that may associate with depression, patients treated with insulin were at almost double risk of depression compared to those not treated with insulin (Crude odds ratio "OR" $=2.26, p<0.001$ ). Additionally, patients treated with three doses or more of insulin per day were more likely to have depression compared to those treated with one dose (Crude $\mathrm{OR}=7.50, \mathrm{p}=0.009$ ). Concerning factors that may associate with anxiety, females were at almost 4 folds risk of anxiety opposed to males (Crude OR $=4.47, \mathrm{p}<0.001$ ). Higher educated patients were less likely to develop anxiety compared to illiterates. Compared to not working women, house wives were more likely to have anxiety (Crude $\mathrm{OR}=6.45, \mathrm{p}<0.001$ ). Patients with duration of diabetes ranged between 1 and 5 years were less likely to be anxious than those whose diabetes duration was less than one year (Crude odds ratio $=0.42, p=0.018$ ). Patients who never practiced physical activity were at nearly 4 -folds risk of anxiety compared to those practiced regular physical activity (Crude odds ratio $=4.07, \mathrm{p}<0.001$ ). Regarding stress, factors that may associate with it were gender as females were at almost double fold of having stress compared to males (Crude odds ratio $=2.19, \mathrm{p}<0.001$ ). Patients with intermediated school educational level were more protective against developing stress compared to illiterates (Crude OR=0.39, p0.006). Patients with good or high financial status were at almost three folded risk for stress compared to those with weak financial status (Crude OR were 3.25, $\mathrm{p}=0.015$ and 3.75, $\mathrm{p}=0.008$ ), respectively. Patients who never practiced physical activity were at nearly 3 -folds risk of stress compared to those practiced regular physical activity (Crude odds ratio $=3.08, \mathrm{p}<0.001$ ). Patients who had social support from their family were less likely to develop stress compared to those without social support (Crude $\mathrm{OR}=0.59, \mathrm{p}=0.035$ ). Patients treated with insulin were at almost double risk of stress compared to those not treated with insulin (Crude OR=1.92, $\mathrm{p}=0.003$ ). Glycated hemoglobin level was not significantly associated with depression, anxiety or stress. Table 3

Among studied demographic and social factors, only marital status and smoking history were significantly associated with glycemic control. Single patients were more likely to have uncontrolled diabetes compared to married patients $(95.2 \%$ versus $65.3 \%), \mathrm{p}=0.025$. Smokers were more likely to have uncontrolled diabetes compared to non-smokers $(87.5 \%$ versus $65.6 \%), \mathrm{p}=0.007$ as shown in table 4 . 
Table 1:-Baseline characteristics of the participants.

\begin{tabular}{|l|l|l|l|}
\hline Age & $18-40$ & 62 & 15.7 \\
& $41-60$ & 207 & 52.4 \\
& $>60$ & 126 & 31.9 \\
\hline Sex & Male & 277 & 70.1 \\
& Female & 118 & 29.9 \\
\hline Education & Illiterate & 112 & 28.3 \\
& Read and write & 41 & 10.4 \\
& Primary school & 67 & 17.0 \\
& Intermediate school & 65 & 16.5 \\
& Secondary school & 69 & 17.5 \\
& University+ & 41 & 10.3 \\
\hline Marital status & Single & 21 & 5.3 \\
& Married & 343 & 86.8 \\
& Divorced & 15 & 3.8 \\
& Widowed & 16 & 4.1 \\
\hline Family size & Alone & 36 & 9.1 \\
& $1-5$ & 94 & 23.8 \\
& 6-10 & 175 & 44.3 \\
& $>10$ & 90 & 22.8 \\
\hline Job status & Not working & 187 & 47.3 \\
& House wife & 77 & 19.5 \\
& Military & 65 & 16.5 \\
& Student & 10 & 2.5 \\
& Others/retired & 56 & 14.2 \\
\hline Financial status & Weak & 31 & 7.8 \\
& Good & 247 & 62.5 \\
& High & 117 & 29.6 \\
\hline Smoking history & Smoker & 32 & 8.1 \\
& Non-smoker & 363 & 91.9 \\
\hline
\end{tabular}

Table 2:-Medical/social characteristics of the participants.

\begin{tabular}{|l|l|l|l|}
\hline Duration of diabetes (years) & $\leq 1$ & 55 & 13.9 \\
& $>1-5$ & 133 & 33.7 \\
& $>5-10$ & 100 & 25.3 \\
& $>10-15$ & 49 & 12.4 \\
& $>15$ & 58 & 14.7 \\
\hline Co-morbidity & No & 215 & 54.4 \\
& Cardiac diseases & 41 & 10.4 \\
& Chronic renal diseases & 11 & 2.8 \\
& Hypertension & 167 & 42.3 \\
\hline Compliance with therapy & Compliant & 346 & 87.6 \\
& Somewhat not compliant & 40 & 10.1 \\
& Not compliant & 9 & 2.3 \\
\hline Physical activity & Regular & 73 & 18.5 \\
& Irregular & 224 & 56.7 \\
\hline Insulin therapy & Never & 98 & 24.8 \\
\hline Number of insulin doses & Yes & 117 & 29.6 \\
\hline (n=117) & 2 & 30 & 25.6 \\
& $\geq 3$ & 70 & 59.9 \\
\hline Social support & No & 17 & 14.5 \\
\hline Glycatedhaemoglobin \% & Yes & 86 & 21.8 \\
& $\geq 7$ & 3099 & 78.2 \\
\hline
\end{tabular}


Table 3:-Factors associated with depression, anxiety and stress among diabetic patients.

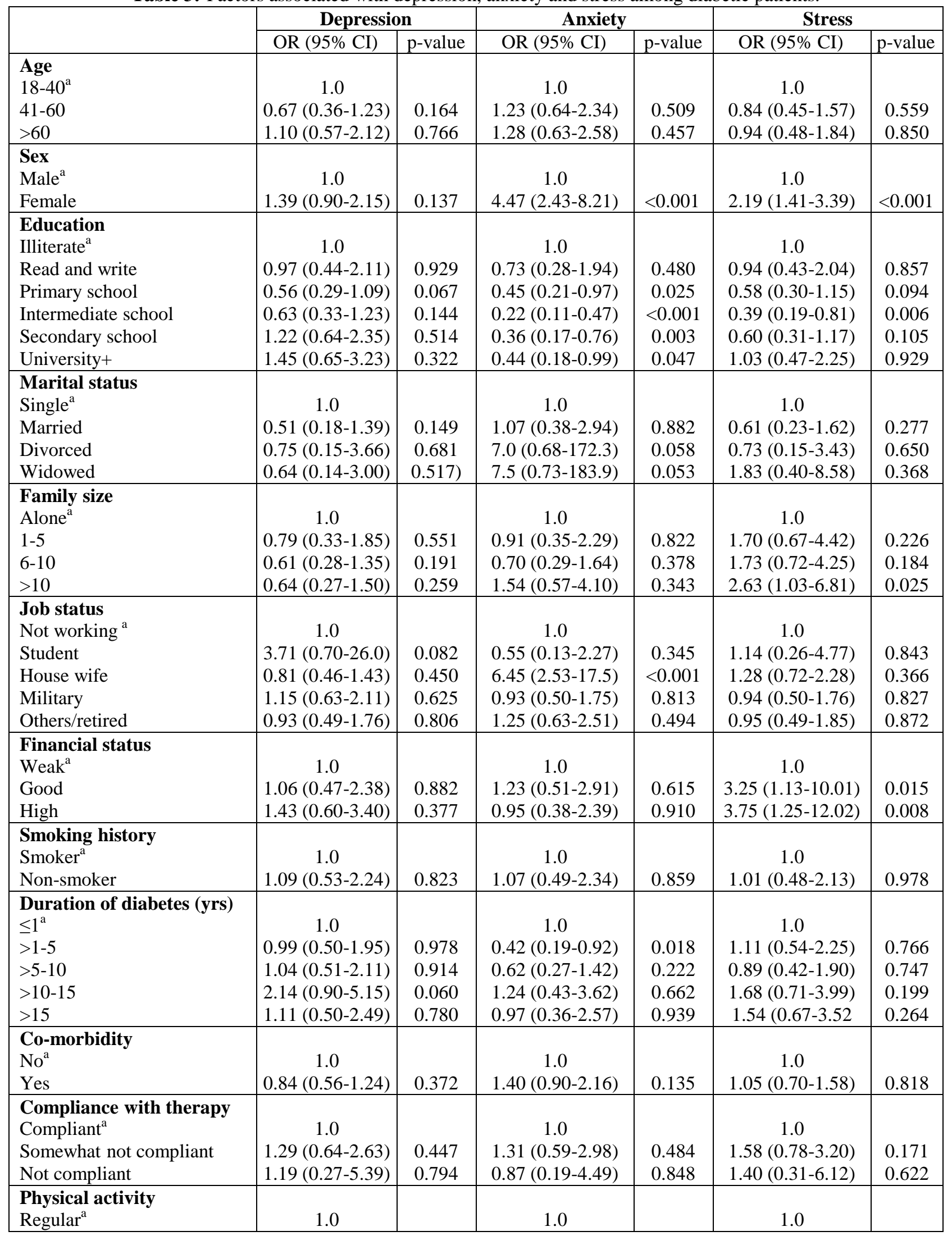




\begin{tabular}{|c|c|c|c|c|c|c|}
\hline Irregular & $1.35(0.77-2.37)$ & 0.267 & $1.19(0.66-2.12)$ & 0.537 & $1.58(0.87-2.89)$ & 0.113 \\
\hline Never & $1.49(0.77-2.87)$ & 0.200 & $4.07(1.81-9.25)$ & $<0.001$ & $3.08(1.56-6.10)$ & $<0.001$ \\
\hline $\begin{array}{l}\text { Social support } \\
\mathrm{No}^{\mathrm{a}} \\
\mathrm{Yes}\end{array}$ & $\begin{array}{c}1.0 \\
0.77(0.46-1.28)\end{array}$ & 0.287 & $\begin{array}{c}1.0 \\
0.76(0.43-1.35)\end{array}$ & 0.326 & $\begin{array}{c}1.0 \\
0.59(0.35-0.98)\end{array}$ & 0.035 \\
\hline $\begin{array}{l}\text { Insulin therapy } \\
\mathrm{No}^{\mathrm{a}} \\
\text { Yes }\end{array}$ & $\begin{array}{c}1.0 \\
2.26(1.44-3.53)\end{array}$ & $<0.001$ & $\begin{array}{c}1.0 \\
1.62(0.99-2.67) \\
\end{array}$ & 0.056 & $\begin{array}{c}1.0 \\
1.92(1.24-2.98)\end{array}$ & 0.003 \\
\hline $\begin{array}{l}\text { Number of insulin doses } \\
1^{\mathrm{a}} \\
2 \\
\geq 3\end{array}$ & $\begin{array}{c}1.0 \\
2.04(0.78-5.36) \\
7.50(1.27-57.3)\end{array}$ & $\begin{array}{l}0.106 \\
0.009\end{array}$ & $\begin{array}{c}1.0 \\
2.54(0.88-7.35) \\
2.70(0.54-15.1)\end{array}$ & $\begin{array}{l}0.052 \\
0.171\end{array}$ & $\begin{array}{c}1.0 \\
1.42(0.55-3.70) \\
2.14(0.55-8.62)\end{array}$ & $\begin{array}{l}0.431 \\
0.214\end{array}$ \\
\hline $\begin{array}{l}\mathbf{H b A}_{1 \mathbf{c}} \% \\
\geq 7^{\mathrm{a}} \\
<7\end{array}$ & $\begin{array}{c}1.0 \\
0.87(0.57-1.32)\end{array}$ & 0.512 & $\begin{array}{c}1.0 \\
1.14(0.73-1.80)\end{array}$ & 0.564 & $\begin{array}{c}1.0 \\
1.03(0.67-1.60)\end{array}$ & 0.884 \\
\hline
\end{tabular}

${ }^{\mathrm{a}}$ Reference category

Table 4:- Demographic and social factors associated with diabetes control $\left(\mathrm{HbA}_{1 \mathrm{c}} \%\right)$.

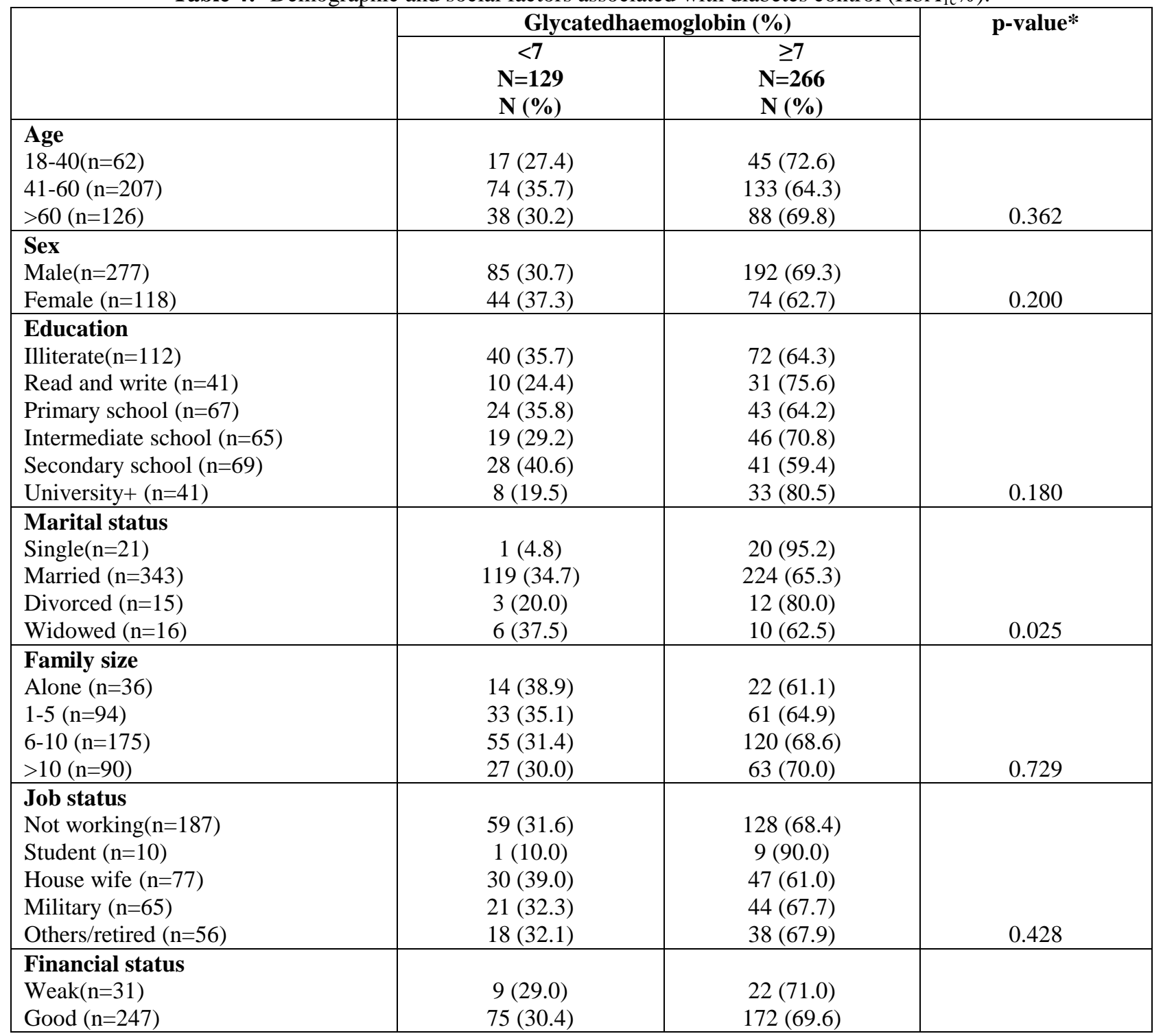




\begin{tabular}{|c|c|c|c|}
\hline High $(\mathrm{n}=117)$ & $45(38.5)$ & $72(61.5)$ & 0.277 \\
\hline $\begin{array}{l}\text { Smoking history } \\
\text { Smoker }(\mathrm{n}=32) \\
\text { Non-smoker }(\mathrm{n}=363)\end{array}$ & $\begin{array}{c}4(12.5) \\
125(34.4)\end{array}$ & $\begin{array}{c}28(87.5) \\
238(65.6)\end{array}$ & $0.007 * *$ \\
\hline $\begin{array}{l}\text { Physical activity } \\
\text { Regular }(\mathrm{n}=73) \\
\text { Irregular }(\mathrm{n}=224) \\
\text { Never }(\mathrm{n}=98)\end{array}$ & $\begin{array}{l}21(28.8) \\
81(36.2) \\
27(27.6)\end{array}$ & $\begin{array}{c}52(71.2) \\
143(63.8) \\
71(72.4) \\
\end{array}$ & 0.233 \\
\hline $\begin{array}{l}\text { Social support } \\
\text { No(n=86) } \\
\text { Yes }(\mathrm{n}=309) \\
\end{array}$ & $\begin{array}{c}26(30.2) \\
103(33.3) \\
\end{array}$ & $\begin{array}{r}60(69.8) \\
206(66.7) \\
\end{array}$ & 0.588 \\
\hline
\end{tabular}

* Chi-square test

** Fischer exact test

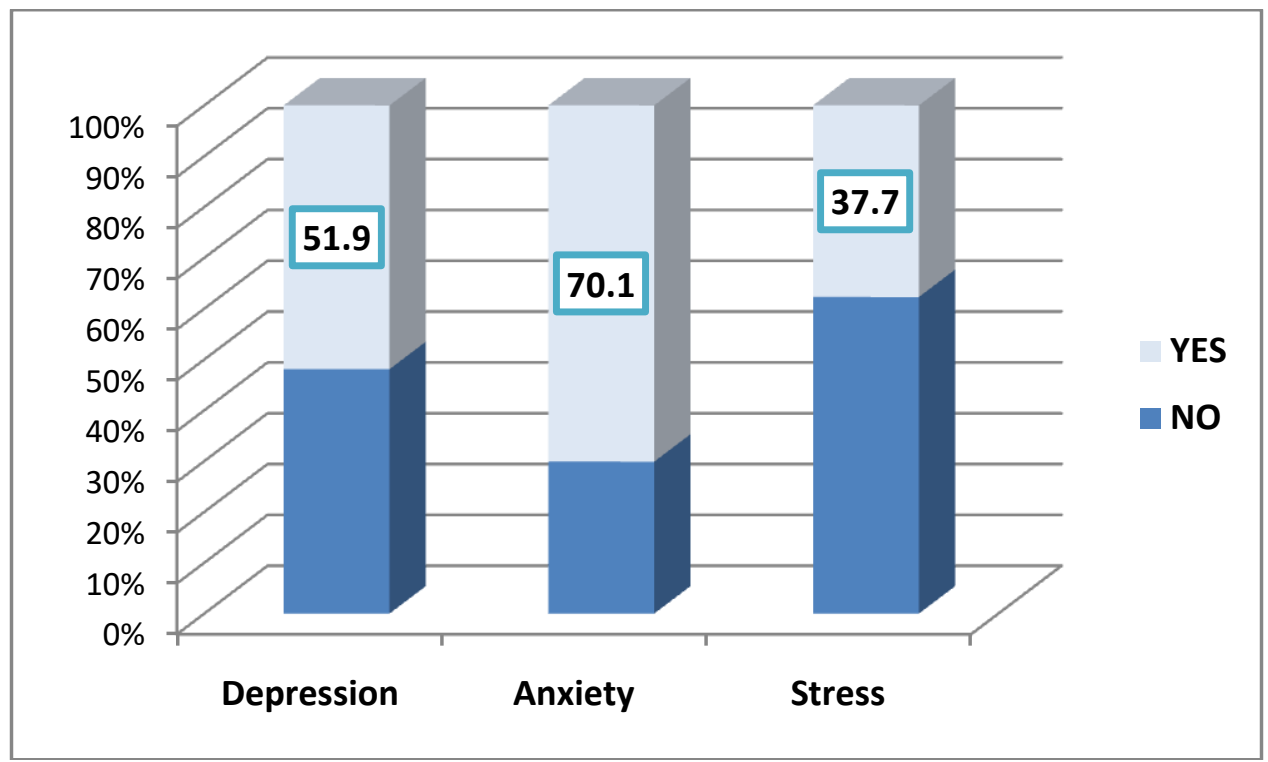

Figure 1:-Prevalence of mood disorders among the participants.

\section{Discussion:-}

It is hypothesized that rates of psychological distress (depression, anxiety and stress) tend to be higher among diabetics than the general population. ${ }^{16}$ The present study was concerned mainly with testing the possible association between psychological distress and glycemic control among diabetics in AhadRufaidah City, Southern Saudi Arabia.

The overall prevalence of depression, regardless its severity among diabetic patients in the present study was $51.9 \%$. In another study carried out in Makkah (2010), the prevalence was $41.9 \% .^{21}$ In Riyadh, AL-Baik et al (2013) reported a prevalence of $45.8 \% .{ }^{22}$ In the Qatif area, a prevalence of $14.5 \%$ for depression among diabetic has been reported. ${ }^{23}$ In Jeddah (2005), it was $48 \% .{ }^{24}$

Worldwide, in Iran 2007 Khamseh et al reported a major depression prevalence of $71.8 \%$ among patients with diabetes (both types; type 1 and type 2). ${ }^{25}$ In North India, Raval et al (2010) reported a prevalence of $41 \%$ of clinically significant depression. ${ }^{26}$ This difference in prevalence rates of depression among diabetic patients between different studies either local or worldwide could be attributed to the fact that some studies included only major depression according to Diagnostic and Statistical Manual of Mental Disorders, IV (DSM VI) criteria while others, like the present study included depression as one category, in addition to different tools used for diagnosis of depression as well as different patients` background criteria.

Regarding determinants of depression, the only significant factor in the present study was insulin therapy as a higher rate of depression among those treated with insulin was reported. Furthermore, depression was more encountered among those treated with more daily doses of insulin. Al-Mouaalamy in Saudi Arabia has reported a significant increase in depression rate among patients treated with insulin. ${ }^{24}$ In addition, Peyrot and Ruben ${ }^{27}$ documented that 
risk to develop depression increased by forty percent among diabetics type 2 who were using insulin. These findings could be explained by the fact that uncontrolled and/or complicated patients were usually using insulin.

Uncontrolled diabetes, as indicated by glycosylated haemoglobin percentage $\geq 7 \%$ was not significantly associated with depression although the rate of depression was higher among them. Other studies reported that uncontrolled diabetes would increase the risk of having depression. ${ }^{28-30}$ However other studies ${ }^{8,31}$ in agreement with the present study did not observe significant differences in average $\mathrm{HbA1C}$ by depression status.

Regarding anxiety, a high rate of anxiety has been reported (70.1\%). This rate is higher than those reported among diabetic patients on Malaysia (31.4\%), ${ }^{32}$ Irealand $(32 \%),{ }^{33}$ Mexico $(52.9 \%)^{34}$ and Pakistan $(57.9 \%) .{ }^{35}$ This could be attributed to the difference between studies in patients`cultural background as well as different tools used in diagnosis of anxiety.

In the present study, higher education has been linked to be a protective factor against anxiety among diabetic patients. The same has been reported by others. ${ }^{33,36,37}$ This could be attributed to the fact that education directs individuals towards proper understanding of disease mechanisms and complications, prompting increased compliance and adherence towards disease treatment for better health outcomes.

In accordance with a previous study by Roupa et al. $(2009)^{38}$ who reported that women appearing to have three times the percentages of anxiety (62\%) in comparison with men $(21.5 \%)$, the present study observed higher significant rate of anxiety among female compared to male diabetic patients.

In the current study, anxiety was significantly higher among newly diagnosed patients than those having a duration between one and five years. This finding is confirmed by observing that anxiety usually became apparent with new diagnosis of diabetes and decreased over time, then could increase again with longer duration as a result of possible complications. ${ }^{39}$

In a study carried out by Balhara et al in India, ${ }^{40}$ a significant association has been approved between HbAlc level and anxiety score which suggests that the quality of care and level of diabetes control might be a better predictor of occurrence of anxiety disorder among those having type 2 diabetes. However, in the present study, we failed to confirm such association.

In the current studies, also anxiety was more observed among house wives than not working patients. This could be a result of home and familial responsibilities of house wives.

Is has been evidenced that regular practicing of physical activity reduces both anxiety and stress. ${ }^{41}$ The possible mechanism for the anxiolytic effects of exercise is via mediation by the endogenous opioid system. Endogenous opioids have a role in the regulation of mood and emotional responses. ${ }^{42}$

In the present study, the prevalence of stress among diabetics was $37.7 \%$. Bener et $\mathrm{at}^{37}$ reported severe stress symptoms prevalence rate of $23.4 \%$ among diabetics which was two-folds higher than healthy controls (10\%)., Additionally, work stress has been reported to be associated with four fold higher risk of DM in Japanese men. ${ }^{43}$ Higher rate has been observed by urRehman and Kazmi in Pakistan $(62.9 \%) .{ }^{44}$ However, in Malaysia, a rate of $12.5 \%$ among Type II Diabetic outpatients has been reported. ${ }^{45}$ The differences were due to the different studies being set in different cultures, demography, disease process, duration of disease and financial situations.

Recently, the association between stress and diabetes have become well known but have been less well researched. Some studies have suggested that stressful experiences might affect the onset and/or the metabolic control of diabetes, but findings have often been inconclusive. ${ }^{46}$

Female patients were more prone to stress compared to males. The same has been documented by others. ${ }^{47,48}$ This could be attributable to gender-specific issues like pregnancy, menstrual cycle changes, post partum and additional stresses such as responsibilities at work and at home, single parenthood, caring for children and aging parents which could all lead to stressful life. 
Moreover, for stress symptoms, illiterate patients were more stressed than moderately educated subjects, those having bigger family size had higher rate of stress, those having higher income were more stressed, those reported social support were more protective against stress and finally those treated with insulin were more stressed.

In summary, there is evidence of high co-morbidity of diabetes and depression, anxiety and stress symptoms in Saudi Arabia.

Important imitations to the present study included the cross-sectional nature of the study design which doesn't permit causation, as well as the use of self-report questionnaires, as literature documented that rate of depression is higher in self-report questionnaires than psychiatric interview. Also, DASS-21 instrument determines only the presence of depression, anxiety and stress symptoms, rather than conducting a diagnostic interview which would have conclusively determined the prevalence of depression, anxiety and stress in the population. Nonetheless, this study has some strengths which make it a worthy contribution to the growing body of literature on DM and psychiatric co-morbidity.

\section{Acknowledgements:-}

The authors would like to thank Dr. Hebah Ahmed Abd-elsadek, clinical nutrition and mental health, High institute of public Health, Alexandria University, Egypt and Roderick Vagillia, clerk, academic affairs department, AhadRufaidah center of family and community medicine for their valuable role in preparation of the final draft of the manuscript.

\section{References:-}

1. Narayan KMV, Boyle JP, Thompson TJ, Sorensen SW, Williamson DF. Lifetime risk for diabetes mellitus in the United States. JAMA 2003; 290:1884-1890.

2. Stoop CH, Spek VRM, Pop VJM, Pouwer F. Disease management for co-morbid depression and anxiety in diabetes mellitus: design of a randomised controlled trial in primary care. BMC Family Practice 2011; $12: 139$.

3. Amos A, McCarthy D, Zimmit P. The rising global burden of diabetes and its complications: Estimates and projections to the year 2010. Diabet Med 1997; 14:S1-S85.

4. Wild S, Roglic G, Green A, Sicree R, King H. Global prevalence of diabetes estimates for the year 2000 and projection for 2030. Diabetes Care 2004; 27(5):1047-53.

5. Elhadd TA, Al-Amoudi AA, Alzahrani AS. Epidemiology, clinical and complications profile of diabetes in Saudi Arabia: A review. Ann Saudi Med 2007;27:241-50.

6. Alqurashi KA, Aljabri KS, Bokhari SA. Prevalence of diabetes mellitus in a Saudi community. Ann Saudi Med. 2011 Jan-Feb; 31(1): 19-23.

7. Kramer JR, Ledolter J, Manos GN, Bayless ML. Stress and metabolic control in diabetes mellitus: methodological issues and an illustrative analysis. Ann Behav Med 2000; 22:17-28.

8. Farrell SP, Hains AA, Davies WH, Smith P, Parton E. The impact of cognitive distortions, stress, and adherence on metabolic control in youths with type 1 diabetes. J Adolesc Health 2004; 34:461-467.

9. Lloyd CE, Dyer PH, Lancashire RJ, Harris T, Daniels JE, Barnett AH. Association between stress and glycemic control in adults with type 1 (insulin-dependent) diabetes. Diabetes Care 1999; 22: 1278-1283.

10. Ciechanowski PS, Katon WJ, Russon JE. Depression and diabetes: impact of depressive symptoms on adherence, function, and costs. Arch Intern Med 2000; 160:3278-3285.

11. Peyrot M, McMurry JF, Kruger DF. A bio-psychosocial model of glycemic control in diabetes: stress, coping and regimen adherence. J Health SocBehav1999; 40:141-158.

12. Surwit RS, Schneider MS, FeinglosMN.Stress and diabetes mellitus.Diabetes Care 1992; 15:1413-1422.

13. Reagan LP, Grillo CA, Piroli GG. The As and Ds of stress: metabolic, morphological and behavioral consequences. Eur J Pharmacol2008; 585:64-75.

14. Bogner HR, Morales KH, Post EP, Bruce ML. Diabetes, depression, and death: a randomized controlled trial of a depression treatment program for older adults based in primary care (PROSPECT). Diabetes Care 2007; 30:3005-3010.

15. American Diabetes Association: Standards of Medical Care in Diabetes--2010. Diabetes Care 2010; 33:S11S61.

16. Engum A, Mykletun A, Midthjell K, Holen A, Dahl AA.Depression and diabetes: a large population-based study of sociodemographic, lifestyle, and clinical factors associated with depression in type 1 and type 2 diabetes.Diabetes Care. 2005 Aug;28(8):1904-9. 
17. SwinscowWH, Cohen JM. Color vision. OphthalmolClin North Am. 2003; 16(2):179-203.

18. Lovibond SH, Lovibond P. Manual for the Depression Anxiety Stress Scales. Sydney: Psychology Foundation; 1995.

19. Taouk M, Lovibond PF, Laub R. Psychometric Properties of an Arabic Version of the Depression Anxiety Stress Scale (DASS). From http://www.psy.unsw.edu.au/Groups/Dass/Arabic/htm. Accessed September 2008

20. American Diabetic Association. Tight diabetes control, 2013. Available at: http://www.diabetes.org/livingwith-diabetes/treatment-and-care/ blood-glucose-control/tight-diabetes-control.html?referrer. Last updated May, 13, 2015

21. Trabulsi FA, Almasaodi KA. Depression among type 2 diabetic patients in Al-Eskan Avenue in Makkah, 2010. American Journal of Research Communication. 2013; 1(10): 49-68

22. AL-Baik MZ, Moharram MM, Elsaid T, Al-Baik S, AlDahan S, Alkhadhrawi N, et al. Screening for depression in diabetic patients. Int J Med Sci Public Health 2014; 3:156-160.

23. Al-Muzien NA, Al-Sowielem LS. Prevalence of depression in diabetics attending primary healthcare centers in the Eastern Province of Saudi Arabia. J Bahrain Med Soc 2014;25(1): 14-18

24. Al Mouaalamy NA. Prevalence of depression among type 2 diabetic patients atteding diabetic clinic at primary health care centers in Jeddah 2004-2005 [dissertation]. Joint Programme of Family and Community Medicine, Jeddah - KSA, 2005.

25. Khamseh ME, Baradaran HR, Rajabali H. Depression and diabetes in Iranian patients: a comparative study. Int J Psychiatry Med. 2007; 37(1): 81-86

26. Raval A, Dhanaraj E, Bhansali A, Grover S, Tiwari P. Prevalence \& determinants of depression in type 2 diabetes patients in a tertiary care centre. Indian J Med Res. 2010 Aug;132:195-200.

27. Peyrot M, Rubin RR. Persistence of depressive symptoms in adult diabetic patients. 1999; $22(3)$ : $448-452$.

28. Xu L, Ren J, Cheng M, Tang K. Depressive symptoms and risk factors in Chinese persons with type 2 diabetes. Arch Med Res 2004; 35(4):301-7.

29. Tellez-Zenteno JF, Cardiel MH. Risk factors associated with depression in patients with type 2 diabetes mellitus. Arch Med Res 2002; 33(1):53-60.

30. Papelbaum M, Moreira RO, Coutinho W, Kupfer R, Zagury L, Freitas S, et al. Depression, glycemic control and type 2 diabetes. Diabetology\& Metabolic Syndrome2011;3:26

31. Lustman P, Anderson R, Freedland K, de Croot M, Carney R, Clouse R. Depression and poor glycemic control. Diabetes Care 2000; 23:934-942.

32. Ganasegeran K, Renganathan P, Abdul Manaf R, Al-Dubai ASR. Factors associated with anxiety and depression among type 2 diabetes outpatients in Malaysia: a descriptive cross-sectional single-centre study. BMJ Open 2014;4:e004794

33. Collins MM, Corcoran P, Perry IJ. Anxiety and depression symptoms in patients with diabetes. Diabet Med 2009;26:153-61

34. Tovilla-Zarate C, Juarez-Rojop I, Jimenez YP, Jiménez MA, Vázquez S, Bermúdez-Ocaña D, et al. Prevalence of anxiety and depression among outpatients with type 2 diabetes in the Mexican population. PLoS ONE2012;7:e36887.

35. Khuwaja AK, Lalani S, Dhanani R, Azam IS, Rafique G, White F. Anxiety and depression among outpatients with type 2 diabetes: a multi-centre study of prevalence and associated factors. DiabetolMetabSyndr 2010; $2: 72$.

36. Ganasegeran K, Renganathan P, Abdul Manaf R, Al-Dubai ASR. Factors associated with anxiety and depression among type 2 diabetes outpatients in Malaysia: a descriptive cross-sectional single-centre study. BMJ Open 2014;4:e04794

37. Bener A, Al-Hamaq AO, Dafeeah EE. High prevalence of depression, anxiety and stress symptoms among diabetes mellitus patients. Open Psychiatry J 2011;5:5-12.

38. Roupa Z, Koulouri A, Sotiropoulou P, Makrinika E, Marneras X, Lahana I, Gourni M. Anxiety and depression in patients with type 2 diabetes mellitus, depending on sex and body mass index. Health Sci J 2009;3:32-40.

39. Almawi W, Tamim H, Al-Sayed N, Arekat MR, Al-Khateeb GM, Baqer A, et al. Association of comorbid depression, anxiety, and stress disorders with Type 2 diabetes in Bahrain, a country with a very high prevalence of Type 2 diabetes. J Endocrinol Invest 2008; 31:1020-4.

40. Balhara YPS, Sagar R. Correlates of anxiety and depression among patients with type 2 diabetes mellitus Indian Journal of Endocrinology and Metabolism 2011;115(5)50-54

41. Anderson E, Shivakumar G. Effects of Exercise and Physical Activity on Anxiety. Front Psychiatry. 2013; 4: 27.

42. Bodnar RJ1, Klein GE. Endogenous opiates and behavior: 2004. Peptides. 2005 Dec;26(12):2629-711. 
43. Kawakami N, Araki S, Takatsuka N, Shimizu M, Ishibashi H. Overtime, psychosocial work conditions and occurrence of non-insulin dependent DM in Japanese men. J EpidemiolCommun Health 1999; 53: 359-63.

44. urRehman A, Kazmi SF. Prevalence and level of sepression, anxiety and stress among patients with type-2 diabetes mellitus. Ann. Pak. Inst. Med. Sci. 2015; 11(2): 81-86

45. Kaur G, Tee GH, Ariaratnam S, Krishnapillai AS, China K. Depression, anxiety and stress symptoms among diabetics in Malaysia: a cross sectional study in an urban primary care setting. BMC Family Practice 2013, 14:69

46. Lloyd C, Smith J, Weinger K. Stress and Diabetes: A Review of the Links. Diabetes Spectrum 2005;18(2):121-127

47. Murakumi J. Gender and depression: explaining the different rates of depression between men and women. PerspectPsychol 2002; Spring: 27-34.

48. Gafvels C, Wandell PE. Coping strategies in men and women with type 2 diabetes in Swedish primary care. Diabetes Res ClinPract 2006; 71: 280-9. 